\title{
Antiknock Performance Study of The CAF60 Military shelter
}

\author{
Chengying Shi ${ }^{1, a}$, Zongshu Mei ${ }^{1, b}$ and Xinghui Cai ${ }^{1, \mathrm{c}}$ \\ ${ }^{1}$ The Second Artillery Engineering University Xi 'an, China \\ ashicy@163.com, b920043582@qq.com, ccaixinghui@163.com
}

Keywords: Military shelter, Load Reduction, structure optimization, antiknock performance, simulation

\begin{abstract}
This paper mainly studies the antiknock performance of the CAF60 military shelter in the flow field of explosion in the building. Compared with the air explosion, there are higher shock wave overpressure and super Overpressure time when bombing in building, so the antiknock performance of the military shelter within buildings put forward higher requirements. According to the current widespread use of the plate structure of military shelter, this paper on the cabin using segmented structure design. Through the finite element simulation calculation, in a simplified pulse load, Comparing the pros and cons of the two kinds of shelter in antiknock performance. Through simulation and calculation, by two cabin under the same loading conditions, getting the stress nephogram, strain nephogram, displacement nephogram, and deflection of the cabin body size. It is concluded that the segmented shelter in the antiknock performance is better than plate shelter and providing an useful reference for CAF military shelter structure optimization.
\end{abstract}

\section{Introduction}

In modern warfare, military shelter in personnel protection, medical aid, electromagnetic interference and "NBC" door plays an important role. Antiknock performance of the shelter is the the one which designers need to pay more attention to, especially for the underground military facilities. When the explosion occurs in the underground facility, the explosion flow field due by tunnel and cavern wall reflection, the shock wave overpressure peak and overpressure time will be a significant increase ${ }^{[1,2]}$, so the antiknock performance of military personnel protective shelter proposed higher requirements.

Currently military shelter mostly made of general plate structure, simple structure, can meet the general load conditions. but it is likely to cause large plastic deformation and damage the plate structure at the center of cabin by dynamic response of explosion shock wave. and larger size, such as CAF60, of Integrated structure module, for general military facilities whose space is extremely limited, there is the problem of inconvenience in transportation. Referring to the structure design of mine rescue capsule ${ }^{[3-5]}$, adopting sectional type structure, divides the whole cabin for several basic unit whose length is less than $1.00 \mathrm{~m}$, and docking of the basic cabin through the external flange on the basic unit, which is suitable in the conditions of transportation, assembling and disassembling in the narrow space of underground military facilities.

\section{Characteristics of Explosive Shock Wave in Buildings}

As the complex wall reflection because of the building structure, The flow field of building internal explosion is the one in which the wave of reflection and incident couple and regenerate a more complex flow field. Generally speaking, if it is a regular structure of the long straight cavern and tunnel, in the early stage of the explosion, flow field is mixed and disorderly. When the shock wave spreads to a certain distance, the flow field will gradually form a stable plane wave. Compared to airburst, the building internal explosion has a larger peak of overpressure and a longer acting time. By numerical calculation software ANSYS LS-DYNA, other conditions are the same, the overpressure curve of a bit in flow field of airburst and building internal explosion as shown in Fig.1 : 

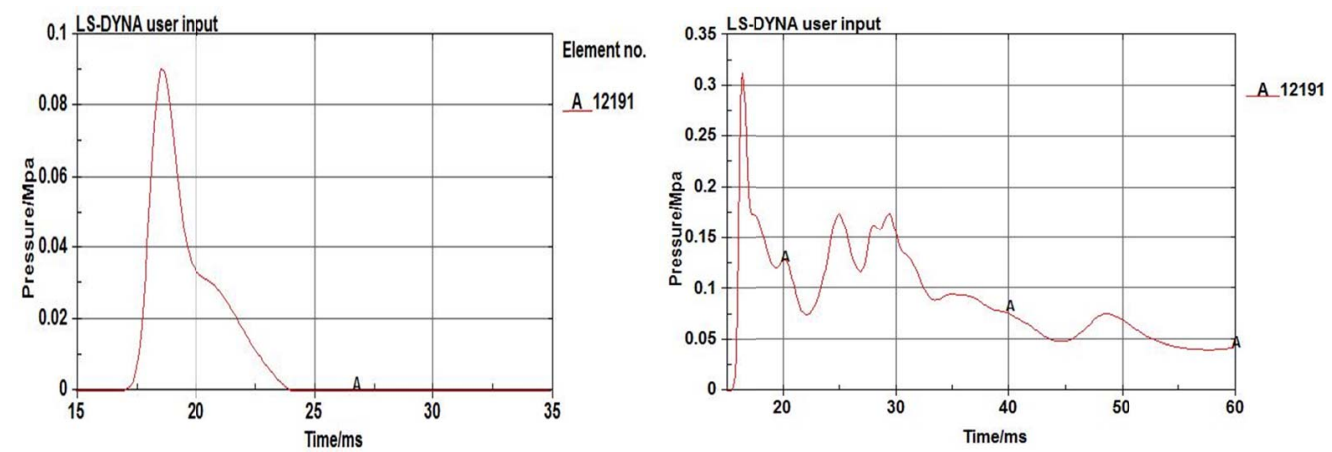

a Airburst

$b$ Explosion in an underground building

Figure. 1 Shock wave overpressure time history curve

As shown in Fig.1, under the same explosive quantity, the overpressure peak in the flow field of building internal explosion is about 2 to 3 times the airburst. Under airburst condition, the action time is about $7 \mathrm{~ms}$; but in the building burst, the duration is about $25 \mathrm{~ms}$ while the overpressure peak keeps in a large value.

\section{Cabin design of Sectional and Plate Structure}

Square sectional structure of military shelter is the basic unit of structure and size as shown in Fig.2 :
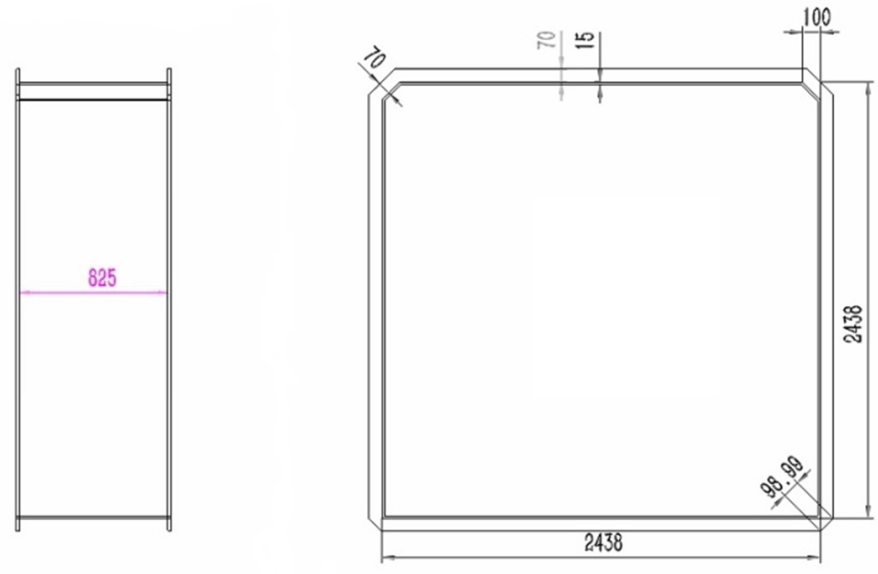

Figure. 2 CAF60 type shelter basic unit size (unit $\mathrm{mm}$ )

As shown in Fig. 2, the basic unit of the cabin body is 865 millimeters long by 15 millimeters thick, the size of flange is 70 millimeters wide and 20 millimeters thick, cabin overall size is $6060 \times 2438 \times 2438$. The design of rear door and escape window is according to the GJB6109-2007 the military shelter universal norms ${ }^{[6]}$, the size of hatch is $1600 \times 800$ and the escape window has a diameter of $600 \mathrm{~mm}$.

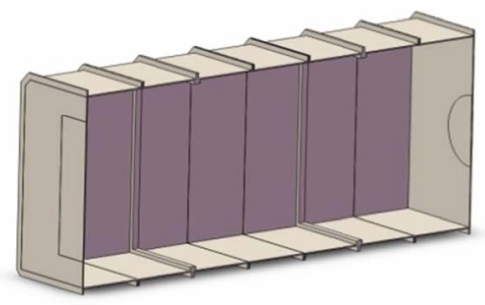

Figure. 3 Cross-section of CAF60 military shelter 
The Finite Element Model. By means of finite element analysis software, establishing the finite element model of segmented cabin and ordinary plate. Cabin unit types using solid 164, material model with elastic plastic model *MAT-PLASTIC-KINEMATIC, cabin material selection of Q345 steel, the mechanical parameters as follows :

Table 1 Cabin material parameters

\begin{tabular}{|l|c|c|c|c|c|}
\hline Name & $\begin{array}{c}\text { Density } \\
{[\mathrm{Kg} / \mathrm{m} 3]}\end{array}$ & $\begin{array}{c}\text { Modulus of elasticity } \\
{[\mathrm{GPa}]}\end{array}$ & Poisson'sratio & $\begin{array}{c}\text { Yield stress } \\
{[\mathrm{MPa}]}\end{array}$ & $\begin{array}{c}\text { Tensile strength } \\
{[\mathrm{MPa}]}\end{array}$ \\
\hline Q345 & $7.85 \mathrm{E} 3$ & 206 & 0.3 & 345 & 630 \\
\hline
\end{tabular}

The unit length is set to $100 \mathrm{~mm}$, using the sweep strategy. After meshing, the elements number of segmented cabin and plate cabin are 9839 and 7809. The finite element model of the cabin as shown in Fig. 4 :

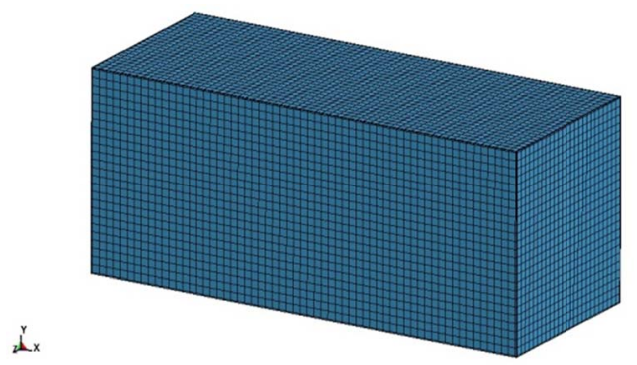

$a$ plate type

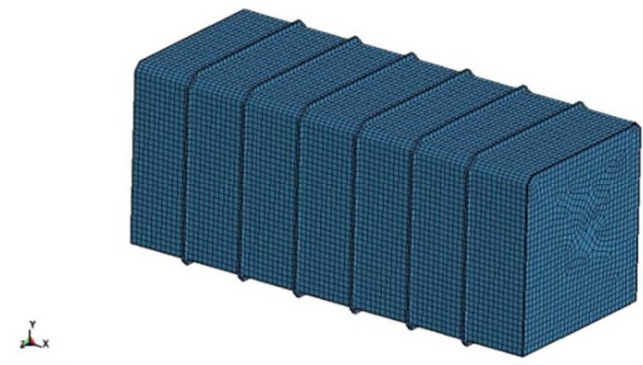

$b$ Segmented type

Figure 4 The finite element model of CAF60 type of military shelter

Load Reduction Method. In building internal explosion, the structure is to bear double loading of shock wave overpressure and quasi static gas pressure ${ }^{[7,8]}$. In the study of the interaction between the shock wave and the structure met with, what should be focused on is the attenuation law of shock wave overpressure over distance, overpressure duration and impulse. As shown in Fig.5, the typical curve of shock wave overpressure over time:

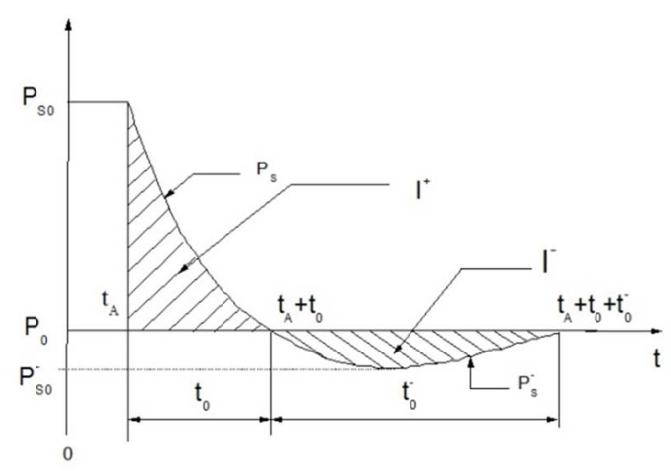

Figure 5 Typical pressure with time decay curve

In Fig.5, the shock wave overpressure is attenuated by the exponential function, and the function expression is : 


$$
\Delta P(t)=\Delta P^{+}\left(1-\frac{t}{T^{+}}\right) e^{-\xi t / T^{+}}
$$

In the formula, $\mathrm{P}^{+}$is the amplitude of shock wave overpressure; $\xi$ is an attenuation coefficient; $\mathrm{T}^{+}$is the positive pressure time. In order to simplify the calculation, in the practical application, the pressure attenuation curve of linear decrease of triangular is used instead of the exponential type of pressure attenuation curve :

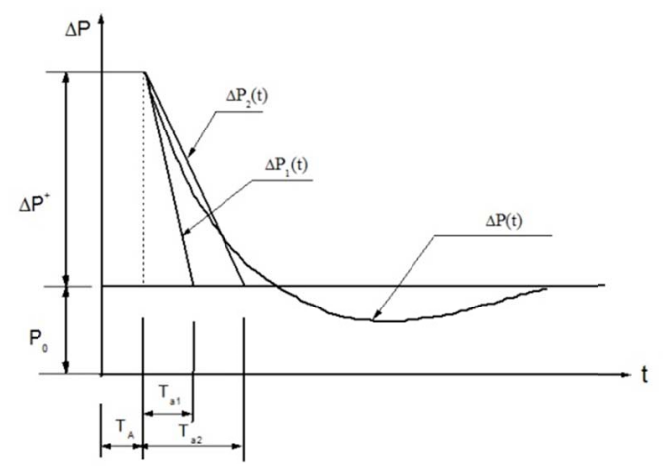

Fig. 6 Equivalent diagram of impact load

Equivalent shock wave function expression :

$$
\Delta P(t)=\Delta P^{+}\left(1-\frac{t}{T_{a}}\right)
$$

Where: Ta is the equivalent action time of shock wave; the $\Delta \mathrm{P}^{+}$is the equivalent peak of shock wave overpressure. When the curve of shock wave overpressure is linearized, keeping the maximum peak of overpressure in the same, the following two methods are used to simplify the study :

1 , If it is in the early stage of overpressure curve occurring the maximum response of the structure or component, it is assumed that the slope of equivalent triangle pulise tangent to the curve of actual overpressure, which can be used to calculate the equivalent time $\mathrm{Ta}_{1}$, guaranteeing the experimental data of pressure and initial decay (initial slope) consistent, as the $\Delta \mathrm{P}_{1}(\mathrm{t})$ is shown in the fig.6, for a long time dynamic load usually using this kind of method.

2 , If the maximum response of structure or component occurs when the overpressure is attenuated to zero, then the equivalent time $\mathrm{Ta}_{2}$ which remains the experimental data consistent with the pressure of the positive impulse, as the $\Delta \mathrm{P}_{2}(\mathrm{t})$ is shown in the fig.6, short-term moving load (pulse load) usually using this kind of method.

Usually, overpressure acting time tends to be very short, generally only milliseconds or tens of milliseconds, tends to be less than the maximum response time of the structure, and its rising time is very short. Therefore, in the calculation of the structure, it can be reduced to a linear decrease of the conventional explosive shock wave by the principle of equal impulse. The peak overpressure $\Delta \mathrm{P}^{+}$ and equivalent time Ta, can be determined by the following formula :

$$
\begin{aligned}
& \Delta P^{+}=1.316\left(\frac{\sqrt[3]{W}}{R}\right)^{3}+0.369\left(\frac{\sqrt[3]{W}}{R}\right)^{1.5} \\
& T_{a}=4.0 \times 10^{-4}\left(\Delta P^{+}\right)^{-0.5} \sqrt[3]{W}
\end{aligned}
$$


Based on the analysis of the characteristics of the overpressure of shock wave in the buildings above, the load diagram in this paper after simplification is as shown in fig.7 :

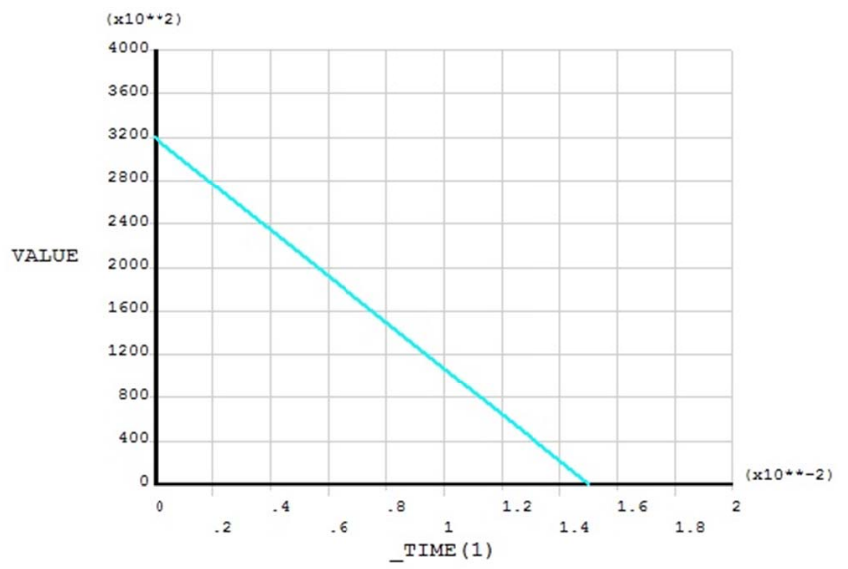

Figure 7 Equivalent load

\section{Result Analysis}

Turn on the cabin before, back and side load applied ${ }^{[9]}$, by LS-DYNA simulation, obtaining the results. Antiknock simulation of plate shelter and sectional shelter results were analyzed by comparing the displacement nephogram and deflection size that segmentation performance superiority of cabin.
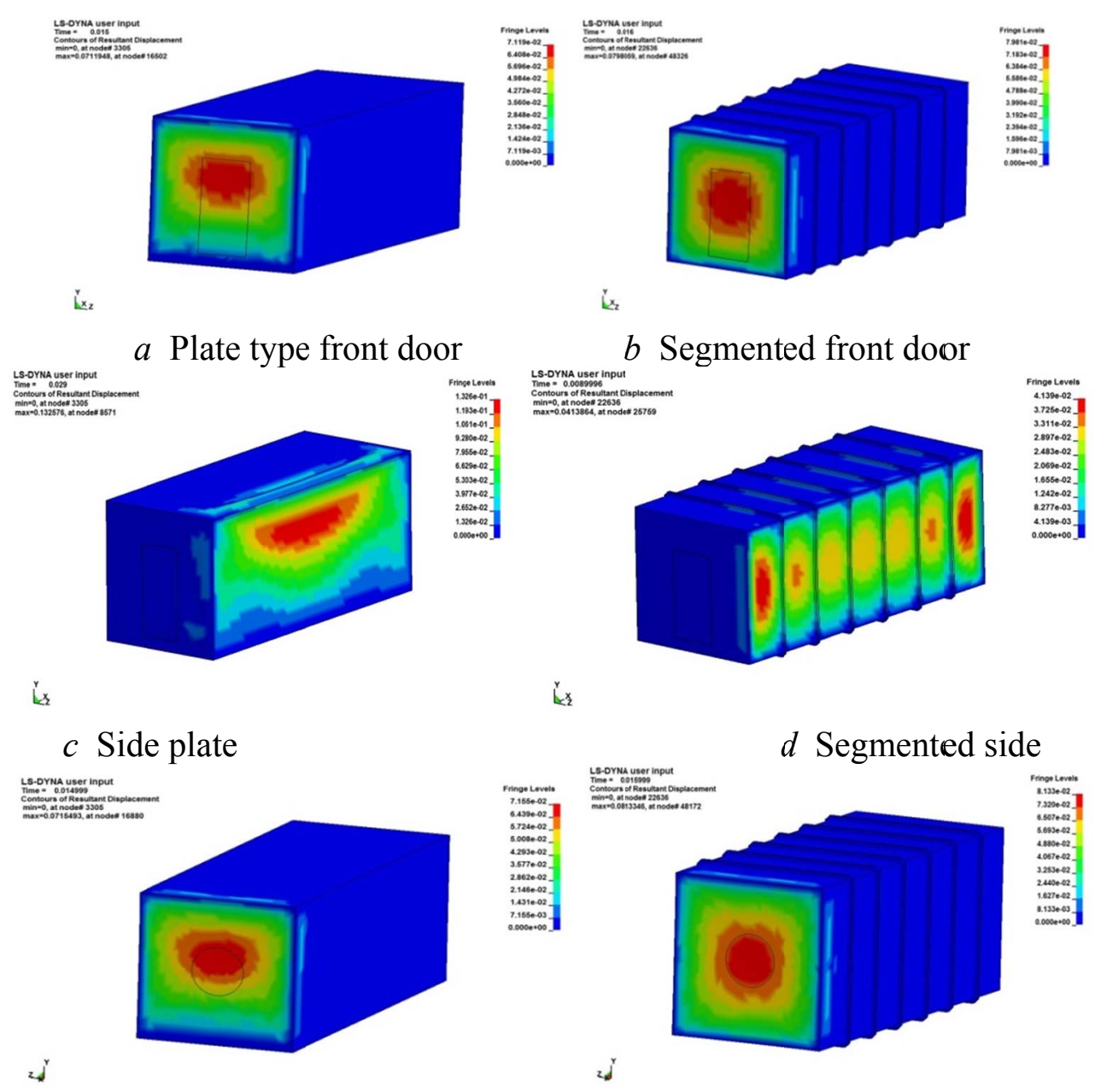

e Plate type rear panel

$f$ Segmented rear panel

Fig. 8 Displacement image 
Directional displacement data of two types of shelter through the LS-DYNA postprocessor are as shown in Table 2 :

Table 2 The maximum deflection

\begin{tabular}{|c|c|c|c|}
\hline \multirow{2}{*}{ Type } & \multicolumn{3}{|c|}{ Deflection ( mm ) } \\
\cline { 2 - 4 } & Front door & $\begin{array}{c}\text { The back } \\
\text { door }\end{array}$ & Side \\
\hline Plate type & 7.9 & 8.3 & 13.2 \\
\hline Segmented type & 7.1 & 7.2 & 4.1 \\
\hline
\end{tabular}

From the above chart, piecewise cabin in the cabin longitudinal load, and load and distribution and a cabin door board, deck in the law to the direction of displacement is almost the same. But in the cabin of lateral load, piecewise cabin than Osaka shelter deck method to displacement is significantly reduced, indicating that the segmented shelter in the antiknock performance of the plate shelter.

\section{Concluding Remarks}

For the antiknock performance of military shelter in the flow field of building burst, it is a problem worthy of study and focus on. The flow field of explosion within buildings is different from airburst flow field, which has a higher overpressure peak of impact wave and a longer positive pressure time. In the structure optimization based on CAF60 type of military shelter, the flange structure of piecewise cabin are not only used as connecting components of the basic unit of cabin but also serves as the role of strong gluten to which cabin body attached. The segmented cabin structure can not only facilitate the transport and assembly of military shelter, but also can effectively enhance the antiknock performance, can be used as a reference structure of blast resistant cabin design.

\section{References}

[1]M. Yong. The numerical simulation of gas explosion shock wave propagation in tunneling roadway [J]. coal technology, 2008, 27 (6): 92-94(in Chinese).

[2]B. Chao. Study on the structural strength of the movable type of coal mine under the explosive load [D]. Shenyang University of Aeronautics and Astronautics, 2012.

[3]PLA General Equipment Department. General specification for military party can. GJB 61092007 [S]. 2007(in Chinese).

[4]H.L.Feng. Simplified calculation of blast shock wave [J]. Shanxi building, 2010, 36 (21): 69-70.

[5]C.J. Wang, Y. Hu and Y.K. Liang. Simulation of antiknock performance analysis of class LSDYNA mine rescue technology [J]. based on the horizon, 2012, 1 (1): 46-47.

[6]D. Meng. Military shelter tightness "three" in the research on the application of [J]. defense technology base, 2008 (12).

[7]T.A. Zheng, C. Wang, W.Z. Jian and Y.S. Li. Military shelter clamped compression rupture energy dissipation theory calculation [J]. Mechanical strength, 2012 (03).

[8]H. Wen, J.J. Fu. Finite element analysis of a large military shelter structure [J]. special vehicle, 2007 (03). 
[9]L. She, Q.T. Guo, X.H. Wang and Y.L. Zheng. A new type of multi objective optimization design for the structure of a new type of honeycomb sandwich structure based on shock wave response (04)(in Chinese). 